\title{
Propolis and its Cosmetic Applications: A Technological Prospection
}

\author{
Karla Bruna Nogueira Torres Barros ${ }^{1,2, *}$, Edilson Martins Rodrigues Neto ${ }^{1,2}$, Marta Maria de França Fonteles ${ }^{1}$ \\ 'Department of Pharmacy, Dentistry and Nursing College, Federal University of Ceara, Fortaleza, CE, BRAZIL. \\ ${ }^{2}$ Catolic Centre University, Quixadá, CE, BRAZIL.
}

\begin{abstract}
Objective: Due to the growing interest and commercialization of products derived from propolis, the present investigation aimed to carry out a prospective study based on the patenting of these products with cosmetic purpose in intellectual property banks in Brazil and worldwide. Methods: There were searched patents with propolis formulations deposited until 2018 at the intellectual property banks: National Intellectual Property Institute (INPI) - Brazil, United States Patent and Trademark Office - United States, World Intellectual Property Organization (WIPO) -Europe and Espacenet. For the search, all patents that included the term "propolis" and "acne" were considered and only the patents for dermatological products were selected. The relevant informations in the patent documents was extracted and organized into tables and graphs generated in the GraphPad Prism program. Results: WIPO was the bank with the largest number of deposits $(43.7 \%)$, whereas in the INPI there were found only three deposits $(2,9 \%)$. The number of patent deposits over the years has been increasing, accentuating from 2014, with expressiveness mainly of
\end{abstract}

China (40.8\%), United States (29.1\%) and South Korea (20.4\%). Regarding the type of product, there were mainly creams and masks, but most of the documents did not have specifications of the product. Conclusion: China is the country that has been depositing patents for dermatological use of propolis, where masks and creams are the most deposited formulations. The number of deposits is still modest, but growth is remarkable and significant.

Key words: Acne, Biotechnology, Patents, Propolis, Prospection.

Correspondence

Prof. Karla Bruna Nogueira Torres Barros,

Professor, Department of Pharmacy, Dentistry and Nursing College, Capitao Francisco Pedro, Fortaleza-CE, BRAZIL.

Phone: +55 8533668000

Email: karlabrunantbarros@gmail.com

DOI: 10.5530/jyp.2019.11.72

\section{INTRODUCTION}

The use of apicultural products by mankind has been dated since antiquity. The interest of the pharmaceutical and cosmeceutical industry in the production of products containing propolis has been increasing. ${ }^{1}$ Propolis is a resinous substance produced by Apis mellifera honey bees from the collection of plant sources mixed with the bee's saliva. It is used as an inner coating material for bee hives keeping them aseptic. ${ }^{2,3}$ The botanical biodiversity of the region where it is produced influences the color, odor and texture of propolis, as well as its chemical characteristics. ${ }^{4}$ The chemical composition of propolis is subject to variations based on botanical biodiversity, seasonality and geographical location. ${ }^{2,5}$ In general, it is composed of resin, wax, essential oils, pollen and other organic compounds, ${ }^{2}$ among them flavonoids (flavones, flavonols and flavonones), terpenoids, aromatic acids, etc. ${ }^{5}$ Therapeutic activities may occur through the synergism of these chemical compounds. ${ }^{5}$ In addition, propolis contains minerals such as $\mathrm{Mg}, \mathrm{Ca}, \mathrm{I}, \mathrm{K}, \mathrm{Na}, \mathrm{Cu}, \mathrm{Zn}, \mathrm{Mn}$ and $\mathrm{Fe}$ and some vitamins such as $\mathrm{A}, \mathrm{B} 1, \mathrm{~B} 2, \mathrm{~B} 6, \mathrm{C}$ and $\mathrm{E} .^{2}$

The biologically active substances of most types of propolis correspond to phenolic compounds, such as flavonoids (European propolis, derived from Populus species), prenylated phenylpropanoids (Brazilian green propolis, derived from Baccharis dracunculifolia) and polyprenylated benzophenonones (Venezuelan propolis, derived from Clusia species). The most produced Brazilian propolis is the green propolis, derived from Baccharis dracunculifolia (Asteraceae), its main constituents are prenylated phenylpropanoids and caffeoylquinic acids. It is consumed in the country and exported to several countries, mainly to Japan and China. ${ }^{4}$

Propolis presents a broad spectrum of biological activity, such as antimicrobial, anti-inflammatory, antitumor, immunomodulatory and healing properties., ${ }^{4,6}$ Propolis presented antibacterial activity against several bacteria, among them Staphylococcus epidermidis, Corynebacterium spp, Propionibacterium spp, bacteroids and Peptostreptococcus spp. ${ }^{2}$

Among skin diseases, acne vulgaris is the most common and affects mainly young individuals. It is a disease with a multifactorial etiology, influenced by follicular hyperkeratinization, sebaceous hyperplasia, bacterial hypercolonization, immune reactions and inflammatory processes. ${ }^{5,7}$ For acne treatment, topical products are widely used, whether or not associated with systemic medication. Often used keratolytics agents, alpha-hydroxy acids, benzoyl peroxide, retinoids, azelaic acid and antibiotics. The antibiotic therapy for P. acnes is the standard, ${ }^{7}$ however, due to the adverse effects and bacterial resistance related to the use of synthetic antibiotics, there is currently a tendency to seek alternative treatments, where the principles natural products are being increasingly exploited. ${ }^{5}$

In this sense, propolis is prominent in the treatment of acne vulgaris. Its anti-inflammatory and antibacterial properties provide the reduction of inflammatory and non-inflammatory lesions, with significant reduction of seborrhoea and oiliness excess of the skin with excellent tolerability. ${ }^{2}$

Concomitant with the new discoveries in relation to propolis, the interest of the industry grows in several countries like Japan, China, Russia, France, Germany and Brazil. Currently there is a wide range of commercial products containing propolis in the formulation, such as sprays, dyes, gels, dentifrices and dermatological creams. The propolis market is on the rise and in rapid expansion, standing out mainly the Brazilian propolis. In 2009, the propolis market in Japan was estimated at US \$ 3

This is an open access article distributed under the terms of the Creative Commons Attribution-NonCommercial-ShareAlike 4.0 License, which allows others to remix, tweak, and build upon the work non-commercially, as long as the author is credited and the new creations are licensed under the identical terms. 
billion, with a substantial participation of products with propolis from Brazil. ${ }^{4}$ Since the end of the last century, the number of publications on propolis has increased, increasing the researchers' knowledge about their biochemistry, botanical origin and biological properties. ${ }^{4}$ Products containing propolis in the formulation are being used with safety and tolerability well described. Its anti-inflammatory and antibacterial properties are being exploited for the development of products for dermatology, for the treatment of acne vulgaris as well as for other skin conditions. ${ }^{2}$

Due to the growing interest and commercialization of products derived from propolis, the present investigation aimed to carry out a prospective study based on the patenting of these products with cosmetic purpose in intellectual property banks in Brazil and worldwide

\section{MATERIALS AND METHODS}

The study of technological prospecting was carried out by analyzing information extracted from patent documents up to the year 2018. The searches were directed to patents deposited with formulations of propolis in the databases of four reference intellectual property banks in the world:

- National Institute of Industrial Property (INPI) - Brazil

- United States Patent and Trademark Office - United States

- World Intellectual Property Organization (WIPO) - Europe

- Espacenet

For the search, all patents that included the term "propolis" and "acne" were considered. The patent reports were selected after reading the title, abstract or report, as inclusion criterion, which only the dermatological patents were selected. Relevant information of the patent documents were extracted and organized into graphs generated in the program GraphPad Prism 6 for interpretation and discussion of the results found. The data represent the distribution of the number of patents by the banks, the annual evolution of the deposits and the types of products.

\section{RESULTS}

Figure 1 shows the distribution of the deposits in the different banks. It is observed that the WIPO was the one with the largest number of deposits, followed by the USPTO. In Brazil represented by INPI, only three deposits were found.

Figure 2 shows the relationship between the number of patent deposits of propolis dermatological products over the years. It is notorious the increase in the number of deposits after the year 2014.

Figure 3 shows the countries depositor of the products. There was a leadership of China, the United States and South Korea mainly.

Figure 4 shows the types of products deposited, predominating creams, processes and masks. Most of the products were not specified exactly.

\section{DISCUSSION}

Several are the alternatives of magisterial and industrialized pharmaceuticals that are available for the acne treatment, among them one can cite propolis. In vitro studies document the high antimicrobial activity of propolis extract at various concentrations (10\%, 5\%, 2.5\%, $1.25 \%$ and $0.625 \%)$ against P. acnes, this antimicrobial action can be correlated with the constituents of propolis, especially flavones and p-coumarin acid derivatives. In addition, propolis has documented healing and antiinflammatory activities which is quite enjoyable in the course of acne treatment. $^{8}$

Many studies now identify the activities of isoflavonoids and report their promising potential in modulating the inflammatory process. Neovestitol, for example, acts both in acute and chronic inflammation, greatly reducing the migration of neutrophils and leukocytes. In addition, pretreatment with neovestitol reduces IL-6 levels and suppression of the production of proinflammatory cytokines. Therefore, neovestitol has a potential antiinflammatory activity. ${ }^{9}$

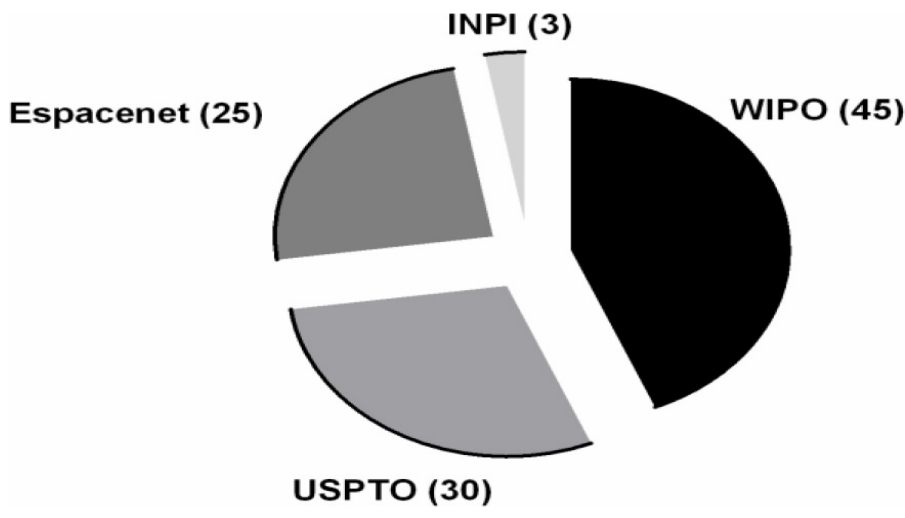

Figure 1: Distribution of patents found in intellectual property banks with the terms "Propolis + acne".

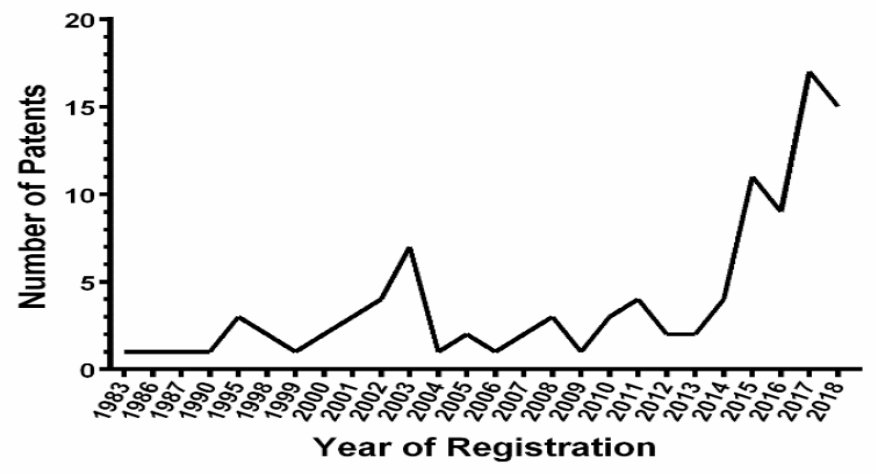

Figure 2: Quantity of patents deposited and registered over the years of products of propolis for dermatological use.

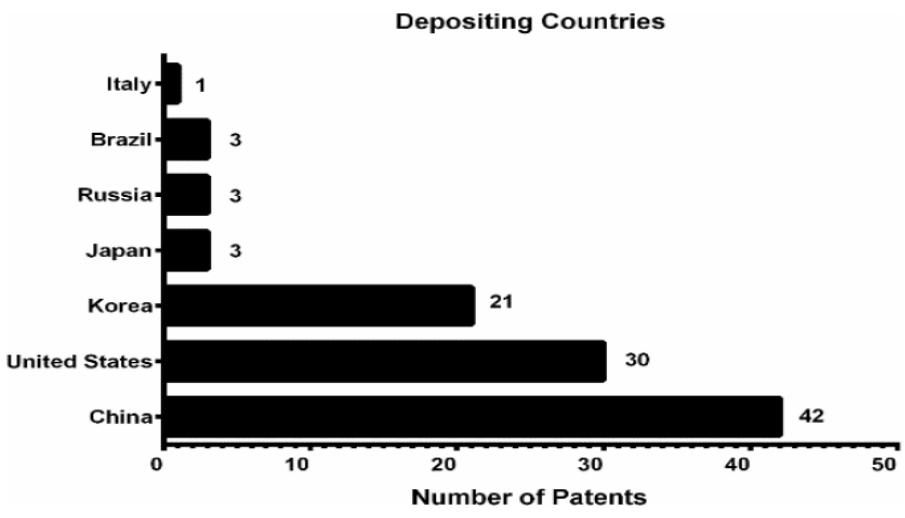

Figure 3: Relationship among depositor countries and quantity of deposits of propolis products for dermatological use.

Since Brazilian red propolis has had its botanical origin characterized, several biological properties have been reported as antioxidant, antimicrobial, cytotoxic and antitumor. The commercial production of this new type of propolis increased rapidly, where consumption is constantly increasing both in the domestic market and in the international market. ${ }^{4}$ Consistent efforts are made to create cosmetic formulations that are less aggressive, with lower levels of toxicity and safer, but which provide the effectiveness of the drugs often used for acne. ${ }^{5,6}$ In the present study, among the products specified in the reports, cream formulations, as well as processes, masks, creams, lotions, soaps and spray were found (Figure 4). Topical agents most commonly used include keratolytics, alpha-hydroxyacids, benzoyl peroxide, retinoids, azelaic acid and antibiotics. ${ }^{7}$ Antibiotics 


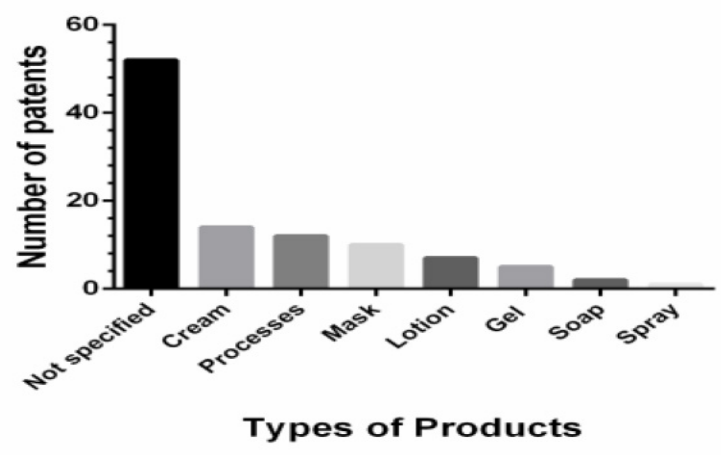

Figure 4: Type of propolis products for dermatological use deposited in intellectual property banks.

that suppress $P$. acnes are the standard treatment for acne, however they are becoming less effective due to antimicrobial resistance. Many natural products are known to have innate antimicrobial action and can be used as alternatives to antibiotics. ${ }^{2} \mathrm{Ali}$ et $a .^{2}$ evaluated the clinical and bacteriological efficacy of topical extracts of propolis in the treatment of facial acne vulgaris in 40 patients. The patients were divided equally into two groups, where group I received treatment with a topical solution of ethanolic propolis extract and group II was treated with only ethanol solution and served as control group. In this study there was a highly significant clinical efficacy of the topical solution of ethanolic propolis extract in the treatment of acne vulgaris, especially in seborrhoea and oiliness. There was a highly significant bacteriological efficacy of the topical solution of ethanolic propolis extract against gram-positive aerobic (Staphylococcus epidermidis) and gram-positive anaerobic bacteria (P. acnes). In addition to being effective, the solution was well tolerated and safe.

Antibiotics are one of the classes of medications used to treat acne. However, possible adverse reactions caused by these drugs make the treatment unpleasant, in addition to the risk of bacterial resistance. Therefore, the use of natural products has been featured in Dermatology. ${ }^{5}$ Barbosa et al. ${ }^{5}$ evaluated in vitro the possible antimicrobial effects of Rosmarinus officinalis essential oil and tincture of propolis on P. acnes strain (ATCC 1969). It can be verified in this study that the essential oil of Rosmarinus officinalis L. did not present antibacterial activity against the P. acnes strain. The dye of propolis had action in several concentrations, being the minimum inhibitory concentration of $0.625 \%$.

The cosmetic industry has invested in the use of propolis used in the treatment of acne, especially in cosmeceuticals, where the application of dermocosmetics containing propolis in concentration of up to $4 \%$ can play a significant role in the prevention and treatment of acne vulgaris due to the anti-inflammatory, antibacterial, healing and immunomodulatory activities, among others. ${ }^{6}$ In the present study it was noticed a large increase in deposits of dermatological products with propolis in the years 2017 and 2018 (Figure 2).

Prospective patent studies are important indicators of the production and trade of products. ${ }^{10,11}$ In the study of Oliveira et al. ${ }^{3}$ on dental resins composed of propolis, it was observed that there is a growing number of patent deposits and the publication of scientific papers, both involving propolis, thus signaling world interest scientific and commercial, especially in China. In the present study, China was also the country with the largest number of deposits, followed by the United States and South Korea.
When compared to the scientific literature, patent filing is small. Brazil, for example, has a great deal of research and technological innovation with products based on propolis, being the country that publishes most on the subject, ${ }^{3,10}$ however, there are few patents deposited (Figure 3). Studies of technological prospecting through patents are considered a relatively recent activity and are currently being used in industrial investments, globalization of the economy and acceleration of advanced technology ${ }^{10}$ In this study the INPI was the bank with the lowest number of deposits, however, these tend to grow, since Brazilian legislation is facilitating the process in research institutions (Figure 1).

\section{CONCLUSION}

After the analysis of patents of products derived from propolis in intellectual property banks, it is concluded that China is the country that has been depositing patents for dermatological use of propolis, masks and creams are the most deposited formulations. The number of deposits is still modest, but growth is remarkable and significant.

\section{ACKNOWLEDGEMENT}

We acknowledge the Federal University of Ceara and Coordenação de Aperfeiçoamento de Pessoal de Nível Superior- Capes 206/2018

\section{CONFLICT OF INTEREST}

The authors declare no conflict of interest.

\section{ABBREVIATIONS}

INPI: National Institute of Industrial Property; USPTO: United States Patent and Trademark Office; WIPO: World Intellectual Property Organization.

\section{REFERENCES}

1. Nascimento TG, Silva PF, Azevedo LF, Rocha LG, Porto ICM, Moura TFL, et al. Polymeric nanoparticles of brazilian red propolis extract: preparation, char acterization, antioxidant and leishmanicidal activity. Nanoscale Res Lett. 2016;11(1):30

2. Ali BMM, Ghoname NF, Hodeib AA, Elbadawy MA. Significance of topical propolis in the treatment of facial acne vulgaris. Egypt J Dermatol Venerol. 2015;35(1):29-36

3. Oliveira JMS, Cavalcanti TFS, Souza LC, Porto ICCM, Nascimento TG, Paiva CL, et al. Uso de própolis no desenvolvimento de resinas dentárias: um estudo prospectivo. Cad Prospec. 2017:10(2):285-99.

4. Salatino A, Salatino MLF. Brazilian Red Propolis: Legitimate Name of the Plant Resin Source. MOJ Food Process Technol. 2018;6(1):21-2

5. Barbosa V, Scheiffer GFC, Cardozo AGL, Pietruchinski E, Santos CZ, Silveira D, et al. Avaliação da atividade antibacteriana do óleo essencial de Rosmarinus officinalis $L$. e tintura de própolis frente à bactéria causadora da acne Propionibacterium acnes. Revista Brasileira De Plantas Medicinais. 2014;16(2):169-73.

6. Matsuchita HLP, Matsuchita ASP. Uso da Própolis na Prevenção e Tratamento da Acne Vulgar. Uniciências. 2015;18(01):19-23.

7. Mazzarello V, Donadu MG, Ferrari M, Piga G, Usai D, Zanetti S, et al. Treatment of acne with a combination of propolis, tea tree oil and Aloe vera compared to erythromycin cream: Two double-blind investigations. Clin Pharmacol. 2018; 10:175-81.

8. Rodrigues NEM, Barros KBNT, Junior FJG, Lobo PLD, Fonteles MMF. Abordagem terapêutica da acne na clínica farmacêutica. Boletim Informativo Geum. 2016;6(3):59-66

9. Franchin M, Colón DF, Cunha MG, Castanheira FVS, Saraiva ALL, Bueno-Silva B, et al. Neovestitol, an isoflavonoid isolated from Brazilian red propolis, reduces acute and chronic inflammation: involvement of nitric oxide and IL-6. Sci Rep. 2016;6:36401.

10. JrFurtado JH, Valadas LAR, Mendonça KS, Oliveira FRD, Gadelha LMU, Fiallos NM. Propolis and Its Dental Applications: A Technological Prospection. Recent Pat Biotechnol. 2018;12(4):288-96.

11. Valadas LAR, Queiroz LR, Bandeira MAM, Filho RDO, Diógenes ÉSG, Fiallos ACM et al. Analyses of deposited and Granted Patents at Federal University of Ceara in Brazil. J Young Pharm. 2017;9(3):307-10 